\title{
Dengue, Zika and Chicungunha: The use of a mathematic concept to develop an educational game for helping on fighting important viral diseases
}

\author{
Dutra T. ${ }^{1}$, Costa, D.P. ${ }^{2}$; Barboza C.F.S. ${ }^{1}$, Alves L. ${ }^{2}$, Castro, H.C. ${ }^{1,2}$ \\ ${ }^{1}$ Pós-graduação em Biociências e Saúde, IOC, FIOCRUZ, RJ, Brazil. \\ ${ }^{2}$ PPBI e CMPDI, Instituto de Biologia, UFF, RJ, Brazil.
}

(c) Scholedge International Journal of Multidisciplinary \& Allied Studies (ISSN 2394-336X), Vol.03, Issue 07 (2016) pg127-134. Published by: Scholedge R\&D Center [www.theSCHOLEDGE.org] [Email: editorial@thescholedge.org]

\begin{abstract}
Dengue is the leading cause of viral death worldwide. The vector Aedes aegypti mosquito is also responsible for Zika and Chincungunha transmission, another very compromising viral diseases. As the understanding of the vector life cycle and its habitat is important for preventing and fighting against these diseases, we propose to use a mathematic concept, graphos, and a problem-based situation (the removal of potential breeding sites for mosquitoes in the player city) to design a computational game that may help on spreading information and to stimulate a players proactive virtual and real behavior. Thus this paper describes the design and construction of an educational computer game called "Graphos against mosquitos," based on graphos, a mathematics theoretical concept. We designed the Graphos game using as the main elements: a child, twelve neighborhood blocks, mosquitoes, streets and containers where mosquitoes lay eggs (tires, cans, bottles, plants with water deposits). In the game, the player (Avatar) is the main element that should "walk in" the streets (edges) of the city, removing the potential breeding grounds for mosquitoes in each block (vertices). As this game is based on the mathematics theoretical concept graphos using two dimensions, the city has two distinct vertices that are the beginning and end of it, which discriminate the beginning and end of the game. The player should remove all containers of each street, avoiding mosquitoes growth and passing only one time for each of them. As containers are removed, the player gains points and is prevented to return to the previous street. In this game the removal of all containers that pose risk of becoming mosquito breeding sites, without coming back to the previous street but only forward, is translatable into " graphos language". When finishing the game properly, it opens a final screen where the player is awarded with a medal. On this screen, the player can write his/her name, being invited to act as a "health worker" no longer in virtual form, but in the real life. Through teaching by using computational material ruled by mathematical concepts such as graphos, we hope to stimulate and contribute for fighting and controlling the vector of these serious viral diseases.
\end{abstract}

\section{Introduction}

Dengue together with Zyka and Chincungunha are currently serious public health problem that affects thousands of people worldwide (World Health Organization, 2016). Tropical countries like Brazil have climatic conditions, including temperature and humidity, combined with urban characteristics that favor the development and spread of the vector, the Aedes aegypti mosquito. 
More than 100 countries on every continent record the presence of the mosquito and cases of these diseases including microcephaly related to Zika (World Health Organization, 2016).

In case of dengue, the virus is a member of the family Flaviviridae and has an incubation period of 8-12 days in the mosquito-groove, after it has bitten an infected individual. After the incubation time, the female is able to transmit the virus to humans and to its eggs that stand in water. Dengue is associated with four serotypes (1-4) and is considered the most important arboviral disease affecting humans today.

The classic symptoms of this disease are: high fever start abruptly, headache, muscle and joints, pain behind the eyes and skin rash. Dengue hemorrhagic fever is a complication arising from the initial framework that can lead to death and its symptoms include high fever, and bone pains. Hemorrhagic phenomena often includes dilatation of the liver and in severe cases, serious and deadly flaws in the clotting process.

Zika virus was described in humans in 1952 and in 2015 a significant number of cases of human infection was reported in Brazil (Morales, 2015; Campos, 2015, WHO, 2015, Marcondes, 2015; Stockholm, 2015). It has a incubation period of 3 to 10 days and the symptoms (fever, joint pain, muscle pain, spots / itching and conjunctivitis) do not occur in all infected individual (Musso, 2015, Oliveira, 2015, Musso, 2015).

The transmission also occurs through sexual contact (Musso, 2015) and the virus is associated with microcephaly in newborn and with Guillain - Barre Syndrome, a serious compromising and fatal condition. Until now, the only way to combat is the vector annihilation responsible for its transmission and thus WHO called for better diagnostics, special attention to pregnant women and strengthening the fight against Aedes Aegypti (Besnard, 2014; Melo, 2016, Ventura, 2016).

According to the literature, the first case of chikungunya in the Americas date from 2013 in Saint Martin in the Caribbean (Cassadou, 2014, Cauchemez, 2014). The Chikungunya virus is transmitted by Aedes albopictus and Aedes aegypit. It presents fever $\left(<38.5^{\circ} \mathrm{C}\right)$ as symptom as well as intense joint and retrorbital pains that last from 10 to 15 days (Paty, 2014; Bortel, 2014; Oliveira, 2015). Joint pain may in fact persist for months.

Since these viral diseases are without specific treatment or vaccine yet, the only current method for prevention is the combat of the vector. Therefore, besides the performance of health services, the direct participation of the population plays a fundamental role, as the habitat of the mosquito is the home environment. Several studies discuss the importance of community involvement not only in implementation but also in defining and planning control activities.

Zyka, Chicungunha and Dengue have been the subject of huge public health campaigns conducted in Brazil. The vector had been eradicated in many countries of the Americas in the 50 and 60, but returned in the 70's for failing to epidemiological surveillance and the social and environmental changes brought by the rapid urbanization.

The explosion of growth of the epidemic in 2014 and 2015 increased educational campaigns that were already being developed, with activities and coordinated actions at federal and state levels. The difficulties of eradicating mosquitoes domiciled, that involves eliminating containers that can store rain water including waste produced in cities (bottles, cans, tires), has required a substantial effort financially and in human and medical resources of the health sector.

The network worldwide computer has been used as a tool to access information about these diseases and eradication of the vector at some schools, and there is the daily creation of sites related to the topic. Based on the interest of adults and children about computer games, our group has been 
working on educational computational games since 2008 (Dutra et al, 2008). In this work we show that the use of mathematics concepts such as graphos may help on planning educational games such the one described herein about destroying focus of this important vector disease.

\section{Methodology}

Initially there was the construction of a library of symbols, drawings, sounds and animations that were used in computer graphics for game production. Graph theory, in which " if and only if the graph has two distinct vertices of odd degree, these are just the beginning and end of the route " was used to generate the scenario and the rules of the game. The main rule is the removal of the potential breeding reservoirs for mosquitoes on the blocks of a neighborhood passing once for every street collecting them in this neighborhood.

\section{Construction of the game}

The production of a database on aspects related to these viral diseases and a library of drawings, sounds and animations was created based on searches for references addressing dengue, Zyca and Chicungunha topics in the National Center for Biotechnology Information (www.ncbi.nlm.nih.gov), Scientific Electronic Library Online (www.scielo.br), ScienceDirect (www.sciencedirect.com) and Periodicals Capes (www.periodicos.capes.gov.br). For the construction of the game board we used the program FLASH-5, while ARQUIVE3 and ACCESS programs were used to construct the database. For the production of the game graphical computing methodologies were used, involving: a) memory access levels, b) Graphic drive, c) complexity and d) interactivity

For the preparation and elaboration of these games we used programs "Ray Game Designer" (by Momor Productions, Inc.) and "Game Maker" (by Mark Overmars, Inc.), following these steps:

1) Import of program elements;

2) Selection of the images to fill the program levels;

3) Definition of animated textures of these images (creation of animations);

4) Creation of mobile elements;

5) Determination of the behavior of moving parts;

6) Creation of the program levels;

7) Validation of the levels to the program;

8) Operating program tests;

9) program compilation for an autonomous function; and

10) Creation of the final version of the program.

After the development of the first prototype, it was subjected to evaluation in ten different nonformal spaces D-Day Dengue (Niterói - RJ) and D-Day Dengue (Rio de Janeiro - RJ). The students were invited to participate and the information was recorded by an observer for the following items:

a) Responsiveness to the game and images;

b) Interpretation of the elements of the game;

c) Preference for each part of the game;

d) play mode - Understanding;

e) Interactivity;

f) Definition of the ideal age.

In order to obtain quantitative data mainly as far as the interpretation of the games of the elements, as well as the preference for the same and the images and the definition of the ideal age, we conducted the evaluation using questionnaires at three of the locations where game was applied. 


\section{Results}

For more effective and efficient prevention against Zyka, Dengue and Chicungunha, health actions should to be linked to social mobilization of communities on the need to keep the environment free of the mosquito. Many of these activities request schools participation and the development of tools for the discussion of these subjects at student and communities levels.

Considering the importance of the information component in programs of health promotion and disease prevention, and also that these viral diseases are serious public health problems, informational messages should be available continuously avoiding the false idea that these diseases only occur in summer. Unfortunately, the campaigns to combat dengue in Brazil are not permanent, and its resumption and intensification on the summer-time period are not enough to eradicate the population growth vector.

Worldwide, one of the key points of these campaigns, and more difficult to succeed, is concerning to the role of communities on eliminating, and not allowing the vector breeding home maintenance. The conventional educational work in this area have been using media, billboards, banners, posters, pamphlets, and lectures in schools and other social centers. At same time, several sites were created on the World Wide Web, the Internet, to allow access to information on these diseases subject.

Based on the interest that usually the children and youth have in computer virtual environment and aiming to inform and trick them to a direct participate in the process of prevention and fight against the vector of Zyka, Dengue and Chicungunha, we produced a game, based on Graphos a mathematical rule, to stimulate the understanding about these diseases and a prevention behaviour.

On that purpose, first we developed the initial scenario of the game graphs that consists of twelve blocks (the outside is also considered as a block) and streets (Fig. 1). Afterwards we create the rules where the child should get all containers where mosquitoes lay eggs in passing once for each street and at the end, the child should go to the outside (Fig. 1). We decorated the landscape with houses and create game elements (Fig. 1) including the kid, the female mosquitos - infected (red), and noninfected (grey), cans, potted plants with water stored, adding them to the game .

On the game, each container removed by the child represents points; The kid is prevented from returning to the street after collecting the reservoirs, taking then a new road to follow. The portals of each are red and turn purple when the kid passes on the street and then blue, when the boy cannot go through that street. When you finish the game properly, it opens a final screen where the child is awarded a medal (Fig.1). The elements that are part of this game are (Fig. 1):

1. Kid.

2. Dengue mosquitoes infected (with red body, indicating that it sucked the blood of an infected person) (2a) and non-contaminated (2b).

3. water reservoirs for mosquito growth (cans, tires, plants and containers accumulating water).

4. Background containing several houses that limit the places where children can spend, representing the neighborhood where she lives.

When the game starts, the kid is entitled with three "lives". The "Clean Up the Neighborhood" is designed to be played individually, although there is the possibility of rotation in relation to participants. The "arrow" keys on the keyboard are used to direct the movements of the kid in the directions left-right and up-down. To exit the game, the kid may press the "esc" on the keyboard. If bitten by an infected mosquito (with the red body), the kid loses a "life" immediately, whereas if a mosquito is not contaminated, nothing will happen to the child.

The objective of this game is to guide the child to stop all reservoirs that could serve as breeding of dengue mosquitoes in the kids neighborhood. This game rely on a mathematical rule called Graphos 
(Bria, 2000) according to which there is only one right way to go before it can destroy all foci without losing any of them. As the kid collects the reservoirs, new streets open whereas others will close. The game can end in two ways:

a) the participant can end collecting all breeding grounds for mosquitoes in the neighborhood and receive an ID card, that the player may print and acts as real agent in the fight against dengue in the neighborhood where the player lives, awakening in the students for acting in the real life;

b) the player loses the third "life", but despite not winning the membership card, he can put his name among the best scores and try again to become an agent in the fight against dengue, playing it again.

Some aspects that may be addressed with this game such as All mosquitoes transmit dengue, Zyca and Chicungunha? How many times may we have dengue? Using this game allows to discuss other issues such as:

- The fact that the participant may only win the game after destroying all reservoirs - since this is the only way to succeed in controlling the mosquitoes, and consequently these viral diseases. It is important to make sure that everybody watch constantly their homes.

- The fact that some mosquitoes do not kill the kid, this can be related to the fact that not all dengue mosquitoes are infected. However, as we do not know which mosquitoes are or not contaminated, we should avoid them all and destroy the reservoirs so as not to procreate. We must remember that a mosquito that is not contaminated today, tomorrow may be contaminated, if it feeds from an infected person.

- The fact that the players become agents to combat these viral diseases in the neighborhood where they live, reinforces the message that the participation of everyone is important in combating the vector and that even children can help.

- The fact of the kid has three lives opportunities, allows to approach the types of dengue viruses (Den-1, Den-2, Den-3 and recently Den-4).

The game was tested with students in a park event and the students' opinions were divided regarding this game. Some of them really liked and understood the subjects (Figure 2). Others complained about being trapped commenting: "I did not like that I was arrested," which relates to the fact that he had not liked the game as for not following the mathematical rule he got arrested in the street. The presence of a teacher with the student at that time gave the chance of discussing the topic. The purpose of the game about "destroying the mosquito focus." was observed by the public that commented that "even a kid can help destroy breeding sites," that achieves one of the most important goals expected to be attended by this game.

\section{Conclusion}

The game Graphos against mosquitos about eliminating Aedes aegypti, the vector of Zyca, Dengue and Chicungunha was constructed and had no problems on tests with students and young kids. It will be donated to schools and is available at the end of the page http://www.biotec.uff.br/?q=content/links-uteis .

\section{Acknowledgments}

We thank the Foundation for Research of the Rio de Janeiro State (FAPERJ), National Council for Scientific and Technological Development (CNPq), Teaching Personnel Improvement Coordination (CAPES) and Federal Fluminense University (UFF) for their financial support. We also thank for H.C.C and C.D. fellowships. 


\section{References}

1. Gubler,D.J. \& Kuno, G. 1997. Dengue And Dengue Hemorrhagic Fever.Cabi. Usa.

2. Teixeira, M.G.; Costa, M.C.N.; Barreto, M.L.; Ferreira, L.D.A.; Vasconcelos, P., 2001. Validação Da Informação Referida Sobre Acometimento De Dengue E Vigilância Epidemiológica. Revista Da Sociedade Brasileira De Medicina Tropical, 34(1): 60-61.

3. Pitta Am, Oliveira Vc 1996. Estratégias De Comunicação Frente Ao Desafio Do Aedes Aegypti No Brasil. Ciência Saúde Col 1 (1).

4. Valla, V. V., 1998. Sobre Participação Popular: Uma Questão De Perspectiva. Cad. Saúde Pública, RJ, 14 (Sup.2): 7-18.

5. Rothman AL. 2004. Dengue: defining protective versus pathologic immunity. J Clin Invest. Apr;113(7):946-51.

6. Guzman MG, Kouri G. 2004 . Dengue diagnosis, advances and challenges. Int J Infect Dis. Mar;8(2):69-80.

7. Putnak R, Porter K, Schmaljohn C. 2003. DNA vaccines for flaviviruses.Adv Virus Res.;61:445-68.

8. Thomas SJ, Strickman D, Vaughn DW. 2003.Dengue epidemiology: virus epidemiology, ecology, and emergence.Adv Virus Res.61:235-89.

9.J. Bria, Grafos No Ensino Fundamental E Médio: Matemática, Interdisciplinaridade E Realidade. Boletim GEPEM , 36 (2000) 11-35.

10.Thais Dutra Silva ; CARDOSO, Fernanda Serpa ; Rodrigues, Carlos R ; MADEIRA, Maria Izabel ; CURRIE, Maulori ; VANNIER, Marcos André ; Castro, Helena C . Jogos virtuais no ensino: usando a dengue como modelo. Revista Brasileira de Ensino de Ciência e Tecnologia, v. 1, p. 58-71, 2008.

11.Thais Dutra Nascimento Silva. Combate à Dengue pela Educação: Desenvolvimento e avaliação do ambiente virtual de aprendizagem para doenças tropicais usando a dengue como modelo.. 2007. o f. Dissertação (Mestrado em Ensino de Biociências e Saúde) - Fundação Oswaldo Cruz, . Orientador: Helena Carla Castro

12.Alfonso J Rodríguez-Morales Zika: the new arbovirus threat for Latin America J Infect Dev Ctries 2015; 9(6):684-685. doi:10.3855/jidc.7230 

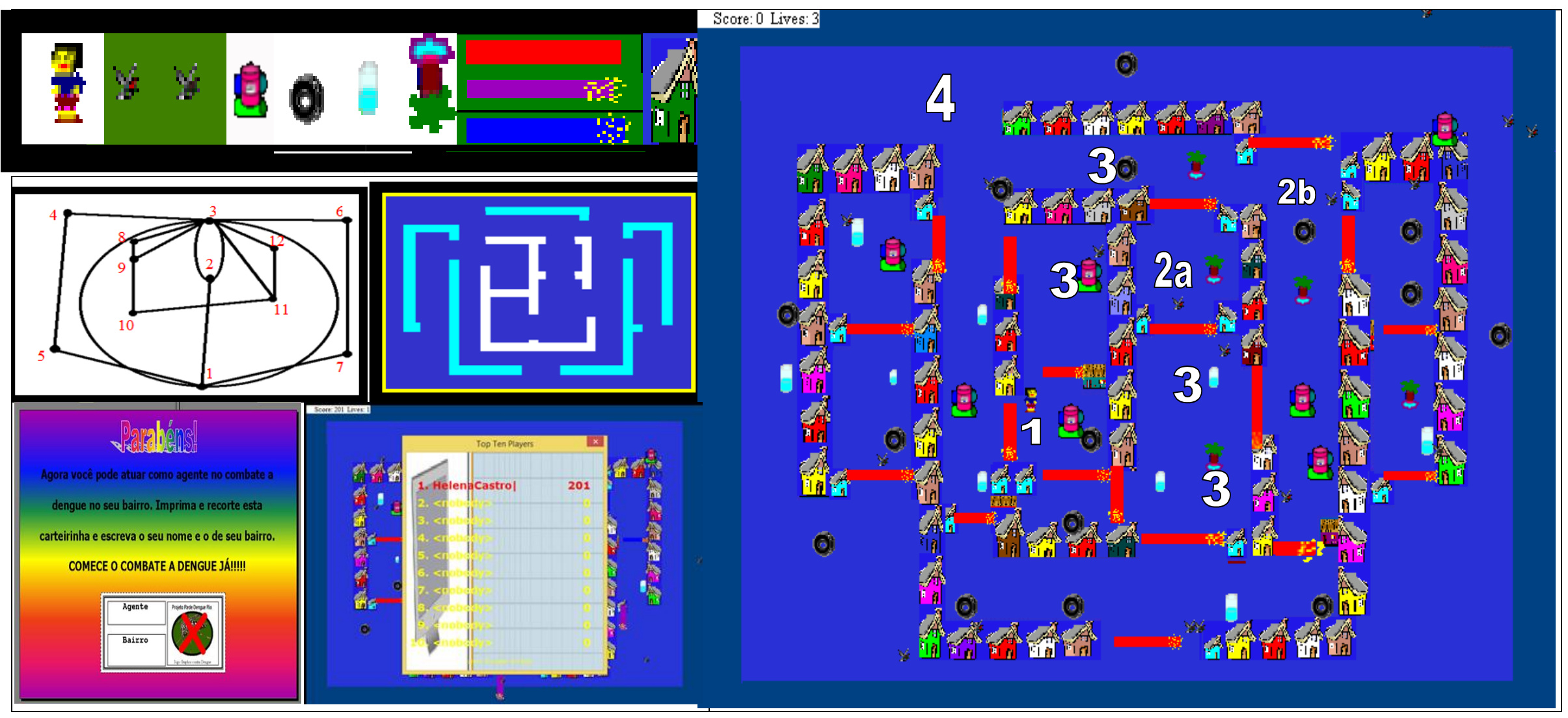

Figure 1: Planning the game" Graphos against mosquitos ". From left to the right - Elements of the game, the board planning using Graphos rules with the 12 streets in the model (white background) and in the limit structure (blue background), window that invite the player to be a agent for collecting the mosquito breeding places in the real world , the final board where the player may add his/her name when finishing the game and on the right the board with the kid (1), the infected (2a) and non-infected mosquito (2b), the water reservoirs (3) and the neighborhood (4). 
Score: 0 Lives: 3

(6)
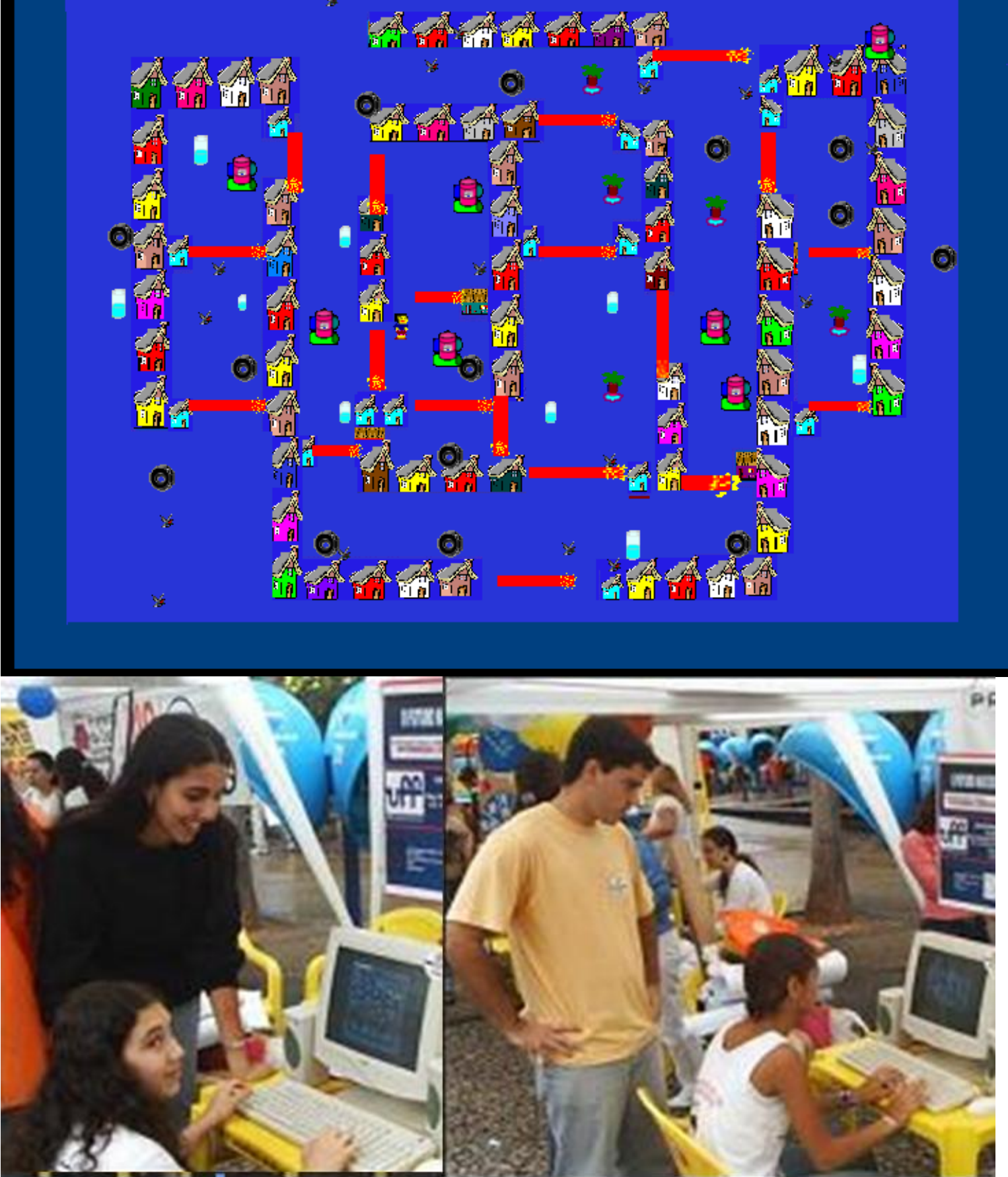

Figura 2: The game" Graphos against mosquitos " (up) and test with students and young children (down). 